\title{
Comparative Study of the Fit Accuracy of Full-Arch Bar Frameworks Fabricated with Different Presintered Cobalt-Chromium Alloys
}

\author{
Hang-Nga Mai, ${ }^{1}$ Tae-Yub Kwon $\mathbb{D}^{2},{ }^{2}$ Min-Ho Hong, ${ }^{2}$ and Du-Hyeong Lee $\mathbb{D}^{1}$ \\ ${ }^{1}$ Department of Prosthodontics, School of Dentistry, Kyungpook National University, 2177 Dalgubeoldae-ro, Jung-Gu, \\ Daegu 41940, Republic of Korea \\ ${ }^{2}$ Department of Dental Biomaterials, School of Dentistry and Institute for Biomaterials Research \& Development, \\ Kyungpook National University, 2177 Dalgubeoldae-ro, Jung-Gu, Daegu 41940, Republic of Korea
}

Correspondence should be addressed to Du-Hyeong Lee; deweylee@knu.ac.kr

Received 12 December 2017; Revised 6 June 2018; Accepted 8 July 2018; Published 5 August 2018

Academic Editor: Despina Deligianni

Copyright (C) 2018 Hang-Nga Mai et al. This is an open access article distributed under the Creative Commons Attribution License, which permits unrestricted use, distribution, and reproduction in any medium, provided the original work is properly cited.

Purpose. This study was to measure the geometric discrepancies that occur during the sintering contraction of presintered Co$\mathrm{Cr}$ alloys in a full-arch bar framework and to compare the variations between alloys from different manufacturers. Materials and Methods. Eighteen implant-supported full-arch bar frameworks were fabricated through a soft-machining process using presintered Co-Cr alloy blocks: Ceramill Sintron (CS), Soft Metal (SM), and Sintermetall (SML) ( $n=6$ for each group). The sintered frameworks were digitized using a structured light scanner, and the scan images were superimposed on the reference design. The geometric discrepancies of the sintered frameworks were three-dimensionally analyzed for horizontal, angular, and internal discrepancies. Kruskal-Wallis and Mann-Whitney U tests were used to compare the discrepancies among the groups $(\alpha=.05)$. Results. Significant differences were found in the geometric discrepancy measurements among the groups. The CS group showed larger horizontal and angular discrepancies, followed by the SM and SML groups $(P<.001)$. The root mean square (RMS) values for internal discrepancy were not statistically different among the groups $(P=.778)$. Conclusion. The geometric discrepancies of full-arch bar frameworks fabricated using the soft-machining process were affected by accuracies in sintering contraction of presintered alloys.

\section{Introduction}

The implant-supported bar overdenture is an effective prosthetic treatment for edentulous jaws, particularly when the implants are misaligned $[1,2]$. Accuracy of a bar framework is essential for longevity of the treatment $[2,3]$. Framework deformation during the fabrication procedure leads to inaccuracies and misfit of the frameworks [4]. The conventional fabrication method for dental prostheses is based on the lost wax technique and casting, and suitable casting alloys should be selected to meet clinical needs [5]. Currently, the cobalt-chromium (Co-Cr) alloy is commonly used for dental prosthesis frameworks [6]. The alloy has a reasonable cost and biocompatibility, as well as exhibiting good mechanical properties [5,7]. The high modulus of elasticity enhances the stress distribution of the framework and decreases the thickness of the framework, thereby leaving more space for artificial teeth and denture base resin $[5,8]$.

The casting technique involves melting of the metal ingots and subsequent cooling for taking the shape of the framework $[6,8]$. The liquefied metal inevitably shrinks during the cooling period [9]. The $\mathrm{Co}-\mathrm{Cr}$ alloys have high melting ranges of the casting alloys [8]. As the solidus temperature increases, more contraction occurs [6]. This inherent feature of the casting technique makes it difficult to accurately fabricate full-arch frameworks using $\mathrm{Co}-\mathrm{Cr}$ alloys in conventional processes. To offset the possible error of contraction process, the use of suitable investment materials and techniques has been recommended [9]. Nonetheless, when the framework is of a large size, the risk of framework misfit is considerably great due to unpredictable contraction of the alloy [6]. To avoid compromising the fit accuracy of the framework, the 


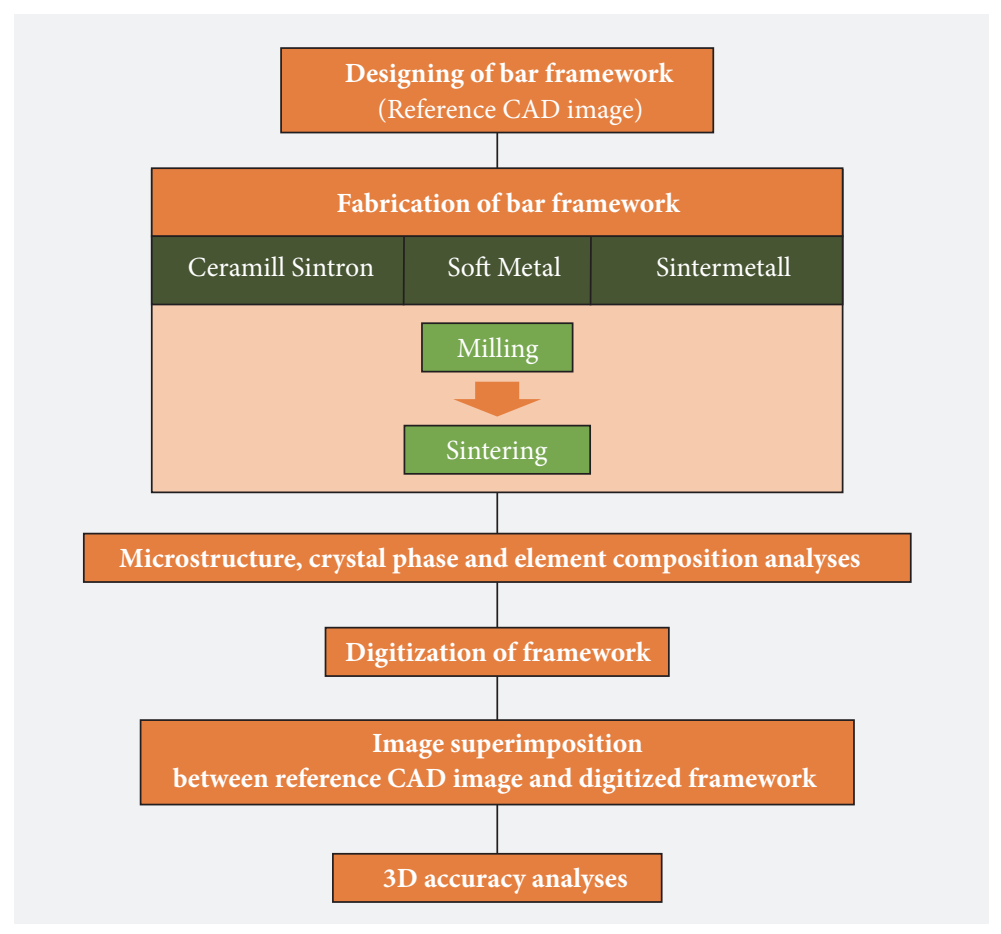

FIGURE 1: Workflow of this study.

framework can be segmented and reconnected $[2,10]$. However, the soldering adjustment decreases the homogeneity of the material and causes new errors in adaptation [11].

Computer-aided design and computer-aided manufacturing (CAD/CAM) are an alternative way to fabricate metal frameworks [12]. CAD/CAM involve fewer manual steps and enable a streamlined manufacturing process in combination with high predictability of the resultant products $[13,14]$. The digital workflow is more efficient than conventional pathways in terms of time and cost benefits [15]. Either fully sintered or presintered metal alloys can be used for milling processes [16]. Fully sintered alloys are milled to the actual size of the frameworks using a hard-machining process $[17,18]$. As there is no contraction after milling, hard machining has demonstrated more precision and predictability than the conventional casting method $[14,19]$. However, the high degree of hardness of such metal alloys makes them more difficult to mill, which can, therefore, shorten the lifespans of tools and increase the maintenance costs of manufacturing devices [18]. Presintered metal alloys are milled to larger size than final one using a soft-machining process, followed by sintering of the milled prosthesis [19]. Because the hardness is lower in the presintered alloys than in the fully sintered alloys, soft machining is more time- and cost-effective than hard machining for producing prostheses $[18,20]$. In addition, the risk of material contamination in the soft machining is low because the block is manufactured using a dry milling process [21].

Sintering of a presintered alloy is essential for achieving the full density and maximum strength of the material [22]. The alloy powder is finely distributed in a binder material
[20]. During the sintering process, the binder material is burned off, and alloy powder particles are sintered without creating a fused phase [23]. This condensation process results in a decrease in volume-the sintering contraction of the milled products-of approximately $11 \%$ [20, 24, 25]. There have been studies evaluating fit accuracy of single crown and multiple-unit fixed dental prostheses (FDPs) fabricated using presintered metal alloys and soft machining [18, 19, 24, 25]. However, few articles have investigated the dimensional accuracy in full-arch bar frameworks fabricated by the presintered alloys. The purpose of this article was to measure the geometric discrepancies between the designed and sintered bar frameworks and to compare variations between alloy blocks from different manufacturers. The null hypothesis was that there was no difference in sintering contraction of presintered alloy blocks and, thus, selection of alloys would not affect the accuracy of the full-arch bar framework.

\section{Materials and Methods}

The overall workflow of this study is described in Figure 1. A full-arch bar framework for an implant-supported overdenture was designed on an edentulous stone model with four implants using dental software (Ceramill Mind; Amann Girrbach AG, Koblach, Austria). The design was saved in standard tessellation language (STL) format as the reference image (Figure 2) and was then delivered to a 5-axis milling machine (Ceramill Motion 2; Amann Girrbach). Metal frameworks were dry-milled from three different presintered Co-Cr alloys: Ceramill Sintron (Amann Girrbach) (CS), Soft Metal (LHK, Chilgok, Korea) (SM), and Sintermetall 
TABLE 1: Co-Cr alloy systems used for fabricating the bar framework.

\begin{tabular}{|c|c|c|c|}
\hline Co-Cr Alloy & $\begin{array}{l}\text { Composition } \\
{\text { (weight } \%)^{*}}^{\text {(weig }}\end{array}$ & $\begin{array}{l}\text { Sintering } \\
\text { furnace }\end{array}$ & Manufacturer \\
\hline $\begin{array}{l}\text { Ceramill } \\
\text { Sintron }\end{array}$ & $\begin{array}{l}\text { Co 66, Cr 28, } \\
\text { Mo 5, Si }<1, \text { Fe } \\
<1, \text { Mn }<1\end{array}$ & $\begin{array}{l}\text { Ceramill } \\
\text { Argotherm }\end{array}$ & $\begin{array}{c}\text { Amann } \\
\text { Girrbach, } \\
\text { Koblach, Austria }\end{array}$ \\
\hline Soft Metal & $\begin{array}{l}\text { Co 63.4, Cr 29, } \\
\text { Mo 5.8, Si 0.8, } \\
\text { other elements } \\
\quad<1\end{array}$ & $\begin{array}{l}\text { Well-Burn } \\
\text { (Denstar) }\end{array}$ & $\begin{array}{l}\text { LHK, Daegu, } \\
\text { Chilgok, Korea }\end{array}$ \\
\hline Sintermetall & $\begin{array}{l}\text { Co } 65, \text { Cr } 27 \\
\text { Mo } 5, \text { C, } N<1\end{array}$ & Sinterofen $300 \mathrm{~S}$ & $\begin{array}{c}\text { Zirkonzahn, } \\
\text { South Tyrol, } \\
\text { Italy }\end{array}$ \\
\hline
\end{tabular}

${ }^{*}$ As provided by manufacturers.

C, carbon; Co, cobalt; Cr, chromium; Co-Cr, cobalt-chromium; Fe, iron; Mn, manganese; Mo, molybdenum; $\mathrm{N}$, nitrogen; $\mathrm{Si}$, silicon.

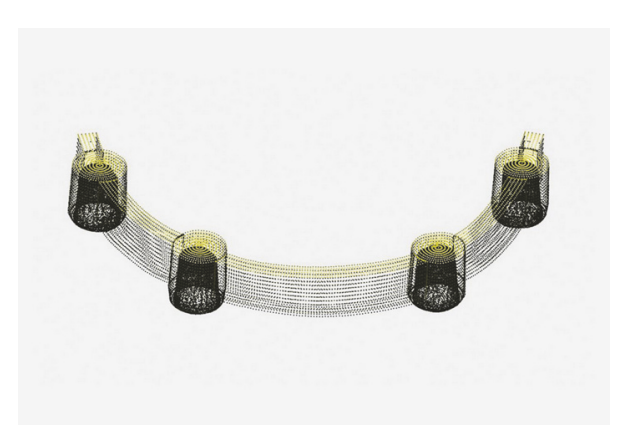

FIGURE 2: Computer-aided design image of bar framework.

(Zirkonzahn, South Tyrol, Italy) (SML). The milled frameworks were subsequently sintered to full density in the corresponding sintering furnaces. Information on the alloys and furnaces used is presented in Table 1. A total of 18bar frameworks were fabricated ( $n=6$ for each of the three groups), and all procedures were conducted following the manufacturers' instructions.

The microstructures of the fabricated specimens of each group were observed using optical microscopy (OM) analysis (MM-40/2U; Nikon, Tokyo, Japan). The crystal structures were evaluated using X-ray diffractometry (XRD) (MAXimaX XRD-7000; Shimadzu, Kyoto, Japan) with an accelerating voltage of $30 \mathrm{kV}$, a $2 \theta$ angle scan range of $30^{\circ}$ to $100^{\circ}$, a beam current of $30 \mathrm{~mA}$, a sampling pitch of $0.02^{\circ}$, a scanning speed of $2^{\circ} / \mathrm{min}$, and a preset time of $0.6 \mathrm{~s}$. For microstructural characterizations and element composition analyses, the specimens were examined by scanning electronic microscopy (SEM) (JSM-6700F; Jeol, Tokyo, Japan) with energy-dispersive X-ray spectroscopy (EDS) under an accelerating voltage of $15 \mathrm{kV}$.

Geometric discrepancies in the metal frameworks were evaluated using three-dimensional (3D) analysis between the reference design and the sintered framework. No posttreatment was done on the surface of sintered frameworks. In the $3 \mathrm{D}$ analyses, the metal frameworks were digitized with a structured light scanner (Breuckmann smartScan;
AICON 3D Systems GmbH, Braunschweig, Germany), and the internal surface image of the attachment component of the framework was segmented from the whole scan data of the bar framework. The same internal surface image was obtained from the reference design. Both images were superimposed using a best-fit registration algorithm function of the dental software package (Geomagic Design X; 3D Systems Inc., Morrisville, NC, USA) (Figure 3).

The outcome parameters for evaluating the geometric discrepancies of sintered frameworks were horizontal, angular, and internal surface discrepancies (Figure 4). The horizontal discrepancy was evaluated by measuring the distance between center points of each attachment component in horizontal plane view. The center point was defined as the intersection of the central longitudinal axis as it passed through the center of the base at a right angle to its plane. To determine angular discrepancy, the angles between the two centerlines of the attachment components from the reference design and the sintered framework were measured. The internal discrepancy between the reference image and the scan image was illustrated in a color-coded map, and the geometric discrepancies were computed for every data point. The root mean square (RMS) was calculated with the following formula [26]:

$$
\mathrm{RMS}=\sqrt{\frac{\sum_{i=1}^{n}\left(x_{1, i}-x_{2, i}\right)^{2}}{n}}
$$

where $x_{1, i}$ is the measuring point $i$ on reference image, $x_{2, i}$ is the measuring point $i$ on the scan image, and $n$ is the total number of measuring points. The significance of discrepancies was illustrated in color codes as follows: green indicated a perfectly matched surface (error $\pm 30 \mu \mathrm{m}$ ); yellow to orange shades indicated the test model was larger than the reference (error between $+30 \mu \mathrm{m}$ and $+150 \mu \mathrm{m}$ ); and light blue to dark blue shades meant the test model surface was smaller than the reference (error between $-30 \mu \mathrm{m}$ and -150 $\mu \mathrm{m})$.

The measured values were compared among the groups. The mean and standard deviation (SD) values in micrometers were calculated for each group. The Kruskal-Wallis test was used to detect quantitative differences among the groups. The Mann-Whitney U test with Bonferroni correction was used to compare statistical differences between the groups $(\alpha=.05)$.

\section{Results}

Figure 5 shows OM images and XRD patterns of the presintered alloys from different manufacturers. Microstructures with round-shaped pores were observed in all samples of OM images. In addition, CS and SM groups showed similar grin sizes. However, SML group showed the finest microstructure compared to both groups. The XRD patterns of the 3 sintered alloys showed $\gamma$ (face-centered cubic, fcc) and $\varepsilon$ (hexagonal close-packed, hcp) matrix phases as well as $\mathrm{Cr}_{23} \mathrm{C}_{6}$ carbide. The Co-based $\gamma$ (fcc) and $\varepsilon$ (hcp) matrix phases were identified with ICDD cards no. 15-806 and no. 05-727, respectively. The peaks indexed as $\mathrm{Cr}_{23} \mathrm{C}_{6}$ metal carbides with a cubic structure were identified by ICDD card no. 35-783. 
TABLE 2: Mean and standard deviation of geometric discrepancies of frameworks.

\begin{tabular}{lccr}
\hline & Ceramill Sintron & Soft Metal & Sintermetall \\
\hline $\begin{array}{l}\text { Horizontal discrepancy } \\
\mu \mathrm{m})\end{array}$ & $94.8(42.2)^{\mathrm{a}}$ & $45.0(19.2)^{\mathrm{b}}$ & $28.5(19.2)^{\mathrm{c}}$ \\
$\begin{array}{l}\text { Angular discrepancy } \\
\text { (degree) }\end{array}$ & $1.4(0.6)^{\mathrm{a}}$ & $0.5(0.3)^{\mathrm{b}}$ & $0.4(0.2)^{\mathrm{b}}$ \\
$\begin{array}{l}\text { Internal discrepancy } \\
(\mu \mathrm{m})\end{array}$ & $132.3(70.8)$ & $148.8(50.7)$ & $<.001$ \\
\hline
\end{tabular}

Different superscript lowercase letters indicate significant differences within a row $(\alpha=.05)$.

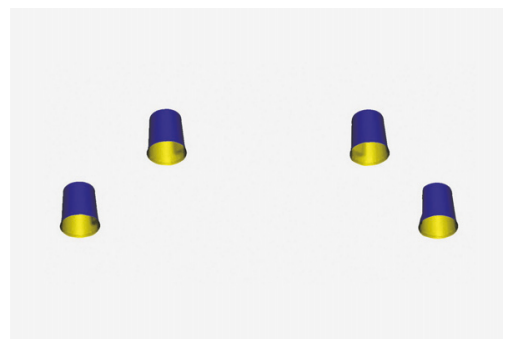

(a)

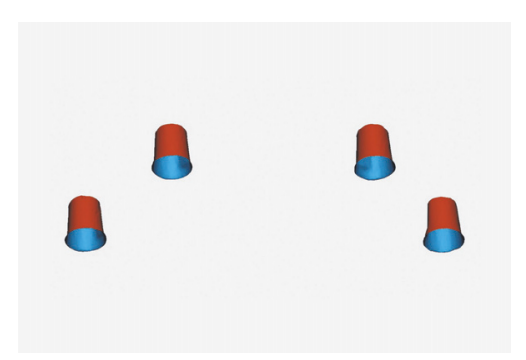

(b)

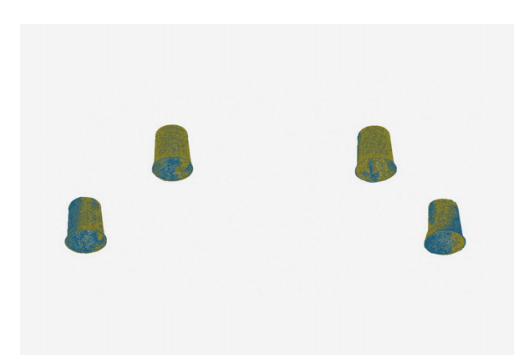

(c)

FIGURE 3: Internal surface of attachment component of framework. (a) Image segmented from reference design. (b) Image segmented from sintered framework. (c) Superimposed image of (a) and (b).

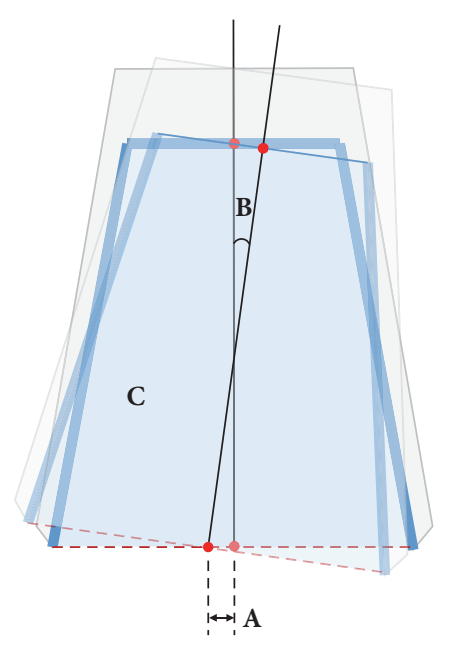

\begin{tabular}{l}
\hline A Horizontal deviation \\
B Angular deviation \\
C Internal surface discrepancy
\end{tabular}

FIGURE 4: Measurement variables. A, horizontal discrepancy. B, angular discrepancy. C, internal surface discrepancy.

The SEM and corresponding EDS mapping images of the all specimens tested were shown in Figure 6. All samples revealed homogeneous dispersion of individual element.

Table 2 presents the geometric discrepancies in the sintered frameworks of the three groups. The horizontal discrepancies in the framework were significantly different from each other $(P<.001)$. The highest discrepancy was found for the CS group, followed by the SM and SML groups. The same tendency was found for the angular discrepancy. The CS group showed the highest discrepancy values $(P<.001)$, and there was no significant difference between the SM and SML groups $(P=.621)$. In terms of internal discrepancy, the mean RMS values were not statistically different among the groups $(P=.778)$. The degree of discrepancy at specific points is illustrated in a colorcoded map (Figure 7). In the SM and SML groups, most of the superimposed surface images were green shades, indicating that the reference design and the scan image corresponded well. The superimposed images of the CS group were represented by reddish or dark bluish ones, showing higher geometric differences with the reference design.

\section{Discussion}

This study evaluated the geometric discrepancies in full-arch bar frameworks fabricated by soft machining of presintered Co-Cr alloy blocks and compared the variations between different alloys. The result of this study showed that the horizontal and angular discrepancies of sintered frameworks differed according to the alloy used. Thus, the null hypothesis-that there is no difference in fabrication accuracy of the bar framework depending on the soft-machining system used-was rejected. The findings of this study correspond well with those found in an earlier accuracy study. Kim et al. [24] evaluated the marginal discrepancy of Co-Cr alloy copings fabricated by CAD/CAM techniques and stated that the marginal fit was material-specific in soft machining. 

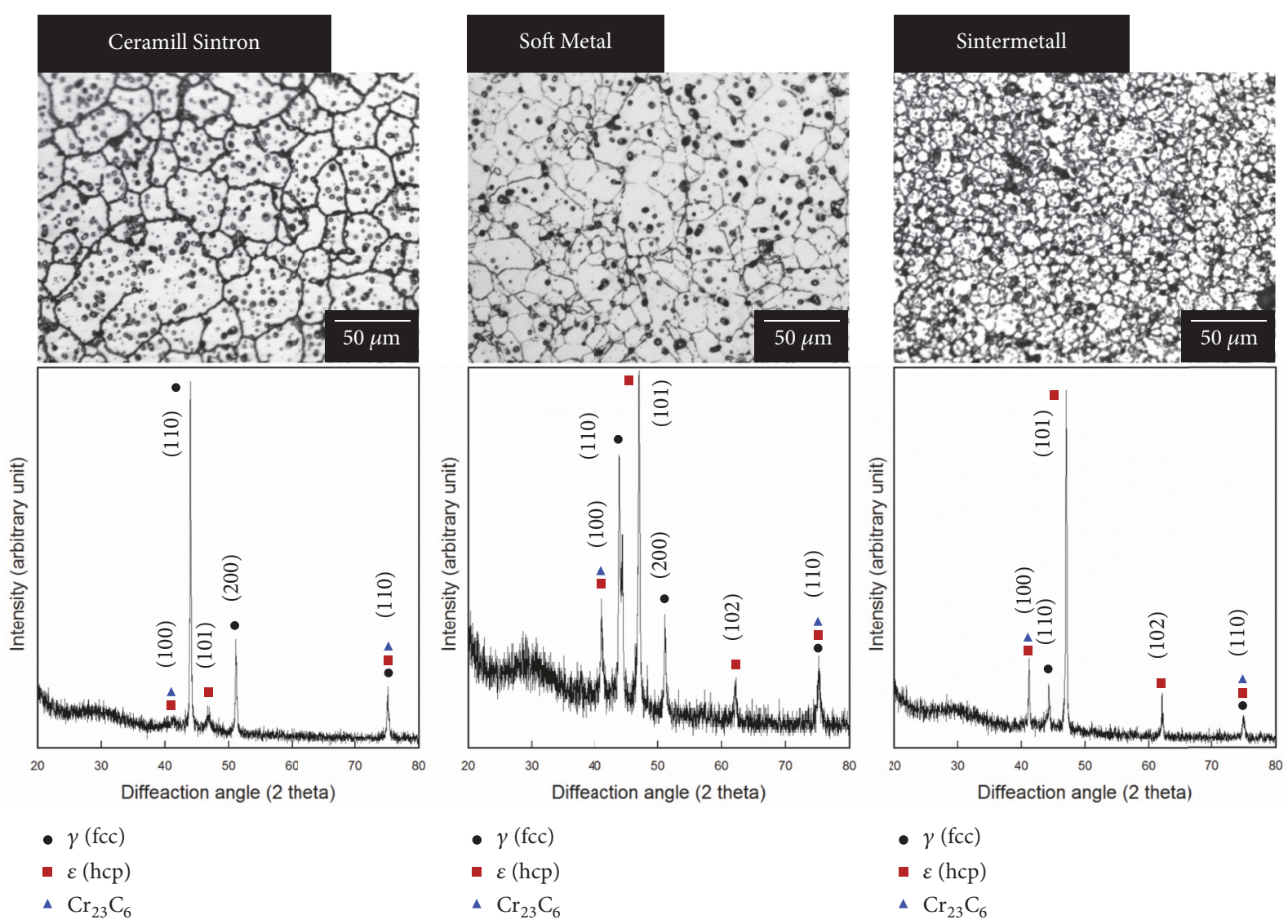

FIGURE 5: Optical microscopy images and corresponding XRD patterns of the Ceramill Sintron, Soft Metal, and Sintermetall specimens.

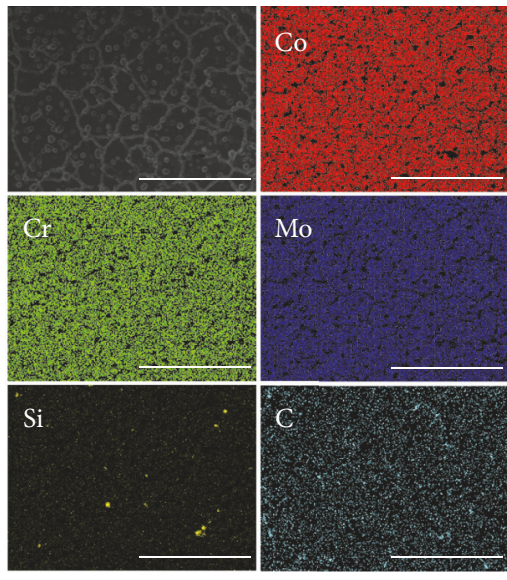

(a)
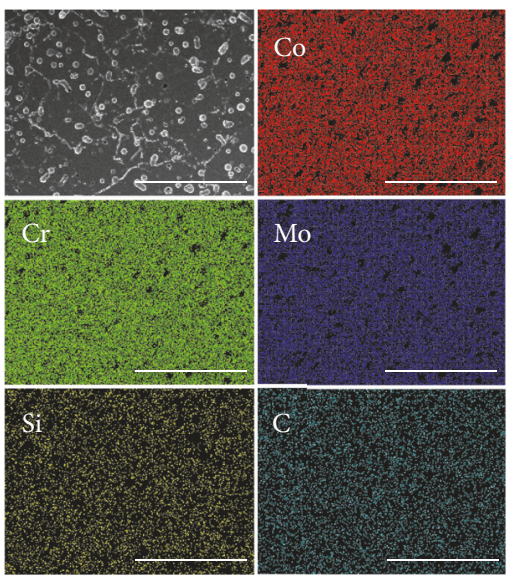

(b)
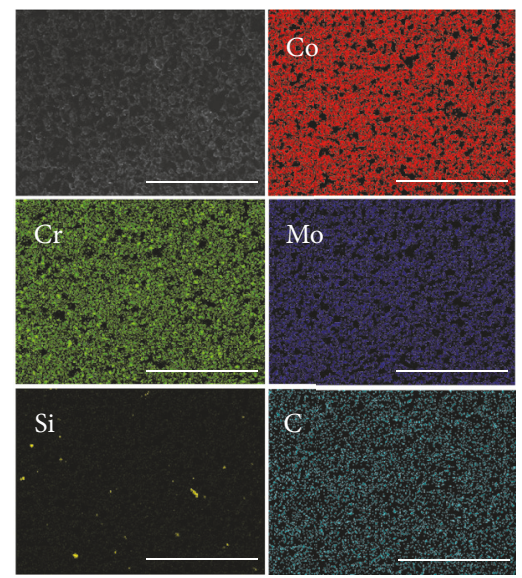

(c)

FIGURE 6: SEM and corresponding EDS mapping image for each group (500×, scale bar $=100 \mu \mathrm{m})$. (a) Ceramill Sintron. (b) Soft Metal. (c) Sintermetall.

In an analysis of XRD pattern, alloys formed $\gamma$ (facecentered cubic) and $\varepsilon$ (hexagonal close-packed) matrix phases as well as $\mathrm{Cr}_{23} \mathrm{C}_{6}$ carbide. In particular, Ceramill Sintron showed a higher peak intensity of $\gamma$ phase and Sintermetall showed a higher peak intensity of $\varepsilon$ phase. These indicated that distinct forms were dispersed. Soft Metal was identified to create $\gamma$ (face-centered cubic) and $\varepsilon$ (hexagonal close-packed) matrix phases. In this way, different grain sizes and phase dispersion might be triggered by different final sintering temperatures depending on manufacturers.

The geometric discrepancies between the reference design and the sintered framework are due to contraction errors in the sintering process [18]. When frameworks are milled in presintered alloy blocks, they are formed larger than 


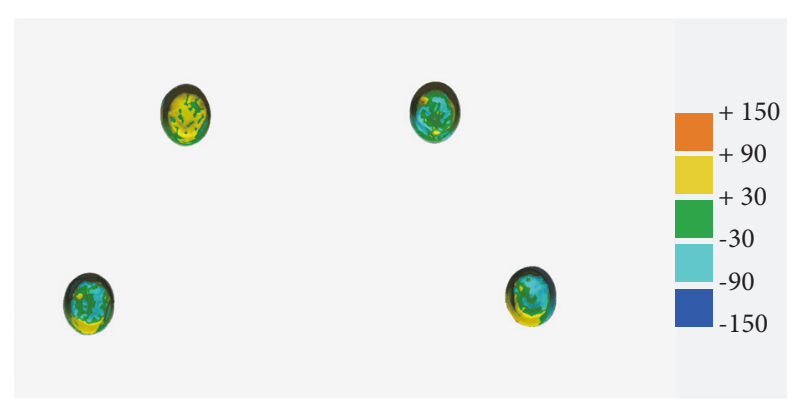

FIGURE 7: Color-coded map showing internal discrepancies in attachment component between reference design and sintered framework. Green indicates a perfectly matched surface (error \pm 30 $\mu \mathrm{m})$. Yellow to orange shades indicate that the test model is larger than the reference design (error between $+30 \mu \mathrm{m}$ and $+150 \mu \mathrm{m}$ ). Light blue to dark blue shades indicate that the test model surface is smaller than the reference design (error between $-30 \mu \mathrm{m}$ and -150 $\mu \mathrm{m})$.

the final size $[18,22,27]$. The expansion ratio is determined by estimating the contraction ratio during the sintering process. Incorrect expansion cannot compensate for real contraction, leading to errors in the entire size [18]. Another error factor is the homogeneity of the presintered alloy block [22]. When the material composition is not homogeneous throughout the block, contraction may occur unevenly. This irregular contraction, depending on the area, causes distortion in large-scale structures [28]. Zhou et al. [29] also reported that a longer span length could lead to reduced adaptation of the framework. Previous articles on presintered alloys assessed the accuracy of prostheses in single or short-span FDPs and concluded that the use of presintered alloys was clinically acceptable $[18,24,25]$. Those findings imply that the general contraction ratio was precisely applied to the expansion ratio in milling. However, the accuracy is limited to a specific region of the block. On the other hand, the present study applied the presintered alloys to a full-arch framework design. Thus, it is possible that uniformity of contraction according to region was also evaluated in the geometric measurements. In other words, this study incorporated more possible sources of error in presintered alloy blocks by enlarging the framework size.

To pinpoint the deformation due to sintering contraction, irrelevant confounding factors were carefully controlled. First, each block from different manufacturers was trimmed using the same milling machine to eliminate effects of the milling process. Second, to minimize scanning errors, the sintered frameworks were digitized using a high-end structured light scanner with an accuracy level of $7 \mu \mathrm{m}$ $[9,30]$. Third, the scan images of the sintered frameworks were directly compared with the reference designs using the best-fit superimposition algorithm in a certified 3D analysis software package [31]. In the literature, the accuracy of prostheses is generally evaluated by measuring the adaptation of a framework to the master cast $[18,24,25]$. Although this is a suitable method for verifying the fit accuracy of prostheses, it should be noted that some errors may occur when the prosthesis is placed and fixed on the master cast. Given the purpose of this present study, direct 3D analyses using the design and the scanned images may be optimal.

To the best of our knowledge, our results are the first reported data on 3D geometric discrepancies of full-arch frameworks stemming from sintering of presintered alloys. Various types of frameworks for multiunit FDPs and removable prostheses should be included in further studies to expand the application of presintered metal alloys. Moreover, large-scale clinical studies are vital for confirming the results of the in vitro studies and for including the number of clinical factors considered.

\section{Conclusion}

Horizontal and angular discrepancies of the full-arch framework that occurred during the sintering process were significantly different depending on the presintered $\mathrm{Co}-\mathrm{Cr}$ alloys used. Special care should be taken in selecting presintered Co-Cr alloys for full-arch frameworks.

\section{Conflicts of Interest}

The authors declare that there are no conflicts of interest regarding the publication of this article.

\section{Acknowledgments}

This research was supported by Basic Science Research Program through the National Research Foundation of Korea (NRF) funded by the Ministry of Science, Information and Communication Technologies (ICT) \& Future Planning (NRF-2014R1A1A1006073).

\section{References}

[1] A. Assaf, M. Daas, A. Boittin, N. Eid, and M. Postaire, "Prosthetic maintenance of different mandibular implant overdentures: A systematic review," Journal of Prosthetic Dentistry, vol. 118, no. 2, pp. 144-152.e5, 2017.

[2] A. Alvarez, P. Lafita, H. de Llanos, A. Gago, A. Brizuela, and J. J. Ellacuria, "A comparison of two soldering techniques on the misfit of bar-retained implant-supported overdentures," Journal of Prosthodontics, vol. 23, no. 2, pp. 163-170, 2014.

[3] S. Bechara, A. Lukosiunas, G. Dolcini, and R. Kubilius, "Fixed full arches supported by tapered implants with knife-edge thread design and nanostructured, calcium-incorporated surface: a short-term prospective clinical study," BioMed Research International, vol. 2017, Article ID 4170537, pp. 1-11, 2017.

[4] L. Hedkvist, T. Mattsson, and L. B. Helldén, "Clinical performance of a method for the fabrication of implant-supported precisely fitting titanium frameworks: A retrospective 5- to 8year clinical follow-up study," Clinical Implant Dentistry and Related Research, vol. 6, no. 3, pp. 174-180, 2004.

[5] K. F. Leinfelder, "An evaluation of casting alloys used for restorative procedures," The Journal of the American Dental Association, vol. 128, no. 1, pp. 37-45, 1997.

[6] J. C. Wataha and R. L. Messer, "Casting alloys," Dental Clinics of North America, vol. 48, no. 2, pp. 499-512, 2004. 
[7] J. C. Wataha, "Biocompatibility of dental casting alloys: a review," Journal of Prosthetic Dentistry, vol. 83, no. 2, pp. 223234, 2000.

[8] H. W. Roberts, D. W. Berzins, B. K. Moore, and D. G. Charlton, "Metal-ceramic alloys in dentistry: a review," Journal of Prosthodontics, vol. 18, no. 2, pp. 188-194, 2009.

[9] A. M. Lacy, H. Fukui, and M. D. Jendresen, "Three factors affecting investment setting expansion and casting size," The Journal of Prosthetic Dentistry, vol. 49, no. 1, pp. 52-58, 1983.

[10] E. Sarfati and J.-C. Harter, "Comparative accuracy of fixed partial dentures made as one-piece castings or joined by solder," International Journal of Prosthodontics, vol. 5, no. 4, pp. 377-383, 1992.

[11] E. Eisenmann, A. Mokabberi, M. H. Walter, and W. B. Freesmeyer, "Improving the fit of implant-supported superstructures using the spark erosion technique," The International Journal of Oral \& Maxillofacial Implants, vol. 19, no. 6, pp. 810818, 2004.

[12] F. Beuer, J. Schweiger, and D. Edelhoff, "Digital dentistry: an overview of recent developments for CAD/CAM generated restorations," British Dental Journal, vol. 204, no. 9, pp. 505-511, 2008.

[13] K. Lee, I. Yeo, B. Wu et al., "Effects of computer-aided manufacturing technology on precision of clinical metal-free restorations," BioMed Research International, vol. 2015, Article ID 619027, pp. 1-5, 2015.

[14] D. G. B. De França, M. H. S. T. Morais, F. D. Das Neves, and G. A. S. Barbosa, "Influence of CAD/CAM on the fit accuracy of implant-supported zirconia and cobalt-chromium fixed dental prostheses," Journal of Prosthetic Dentistry, vol. 113, no. 1, pp. 2228, 2015.

[15] T. Joda and U. Brägger, "Digital vs. conventional implant prosthetic workflows: a cost/time analysis," Clinical Oral Implants Research, vol. 26, no. 12, pp. 1430-1435, 2015.

[16] H. Kocaagaoglu, H. Albayrak, H. I. Kilinc, and H. O. Gumus, "Effect of repeated ceramic firings on the marginal and internal adaptation of metal-ceramic restorations fabricated with different CAD-CAM technologies," Journal of Prosthetic Dentistry, vol. 118, no. 5, pp. 672-677, 2017.

[17] F. Zarone, M. Ferrari, and T. Joda, "The complete digital workflow in fixed prosthodontics: a systematic review," $B M C$ Oral Health, vol. 17, no. 1, p. 124, 2017.

[18] J.-K. Park, H.-Y. Kim, W.-C. Kim, and J.-H. Kim, "Evaluation of the fit of metal ceramic restorations fabricated with a presintered soft alloy," Journal of Prosthetic Dentistry, vol. 116, no. 6, pp. 909-915, 2016.

[19] H. Kocaağaoğlu, H. İ. Kılınç, H. Albayrak, and M. Kara, "In vitro evaluation of marginal, axial, and occlusal discrepancies in metal ceramic restorations produced with new technologies," Journal of Prosthetic Dentistry, vol. 116, no. 3, pp. 368-374, 2016.

[20] D.-H. Lee, B.-J. Lee, S.-H. Kim, and K.-B. Lee, "Shear bond strength of porcelain to a new millable alloy and a conventional castable alloy," Journal of Prosthetic Dentistry, vol. 113, no. 4, pp. 329-335, 2015.

[21] J. K. Jung, "An evaluation of the gap sizes of 3-unit fixed dental prostheses milled from sintering metal blocks," BioMed Research International, vol. 2017, Article ID 7847930, pp. 1-8, 2017.

[22] P. Kohorst, H. Brinkmann, J. Li, L. Borchers, and M. Stiesch, "Marginal accuracy of four-unit zirconia fixed dental prostheses fabricated using different computer-aided design/computeraided manufacturing systems," European Journal of Oral Sciences, vol. 117, no. 3, pp. 319-325, 2009.

[23] B. Stawarczyk, M. Eichberger, R. Hoffmann, F. Noack, J. Schweiger, D. Edelhoff et al., "A novel CAD/CAM base metal compared to conventional CoCrMo alloys: an in-vitro study of the long-term metal-ceramic bond strength," Oral Health and Dental Management, vol. 13, no. 2, pp. 446-52, 2014.

[24] E.-H. Kim, D.-H. Lee, S.-M. Kwon, and T.-Y. Kwon, "A microcomputed tomography evaluation of the marginal fit of cobaltchromium alloy copings fabricated by new manufacturing techniques and alloy systems," Journal of Prosthetic Dentistry, vol. 117, no. 3, pp. 393-399, 2017.

[25] B. Pasali, D. Sarac, N. Kaleli, and Y. S. Sarac, "Evaluation of marginal fit of single implant-supported metal-ceramic crowns prepared by using presintered metal blocks," The Journal of Prosthetic Dentistry, vol. 119, no. 2, pp. 257-262, 2018.

[26] O. Schaefer, D. C. Watts, B. W. Sigusch, H. Kuepper, and A. Guentsch, "Marginal and internal fit of pressed lithium disilicate partial crowns in vitro: a three-dimensional analysis of accuracy and reproducibility," Dental Materials, vol. 28, no. 3, pp. 320-326, 2012.

[27] C. E. Besimo, H. P. Spielmann, and H. P. Rohner, "Computerassisted generation of all-ceramic crowns and fixed partial dentures," International Journal of Computerized Dentistry, vol. 4, no. 4, pp. 243-262, 2001.

[28] J. Kunii, Y. Hotta, Y. Tamaki et al., "Effect of sintering on the marginal and internal fit of CAD/CAM-fabricated zirconia frameworks," Dental Materials, vol. 26, no. 6, pp. 820-826, 2007.

[29] Y. Zhou, Y. Li, X. Ma, Y. Huang, and J. Wang, "Role of span length in the adaptation of implant-supported cobalt chromium frameworks fabricated by three techniques," The Journal of Advanced Prosthodontics, vol. 9, no. 2, pp. 124-129, 2017.

[30] T. P. Kersten, H.-J. Przybilla, M. Lindstaedt, F. Tschirschwitz, and M. Misgaiski-Hass, "Comparative geometrical investigations of hand-held scanning systems," in Proceedings of the 23rd International Archives of the Photogrammetry, Remote Sensing and Spatial Information Sciences Congress, ISPRS 2016, pp. 507514, Czech Republic, July 2016.

[31] B. E. Dahl, H. J. Ronold, and J. E. Dahl, "Internal fit of single crowns produced by CAD-CAM and lost-wax metal casting technique assessed by the triple-scan protocol," Journal of Prosthetic Dentistry, vol. 117, no. 3, pp. 400-404, 2017. 


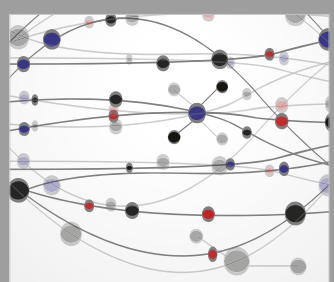

The Scientific World Journal
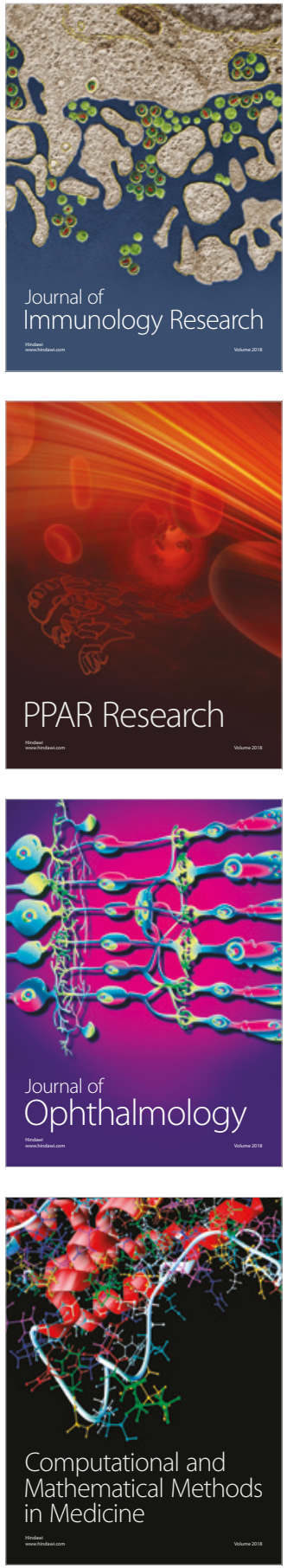

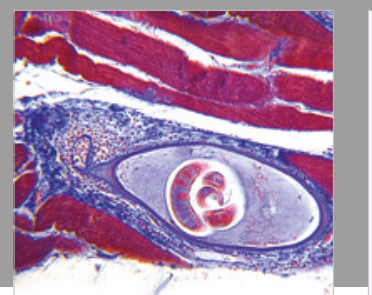

Gastroenterology Research and Practice

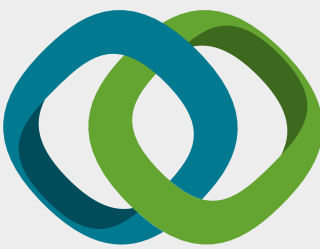

\section{Hindawi}

Submit your manuscripts at

www.hindawi.com
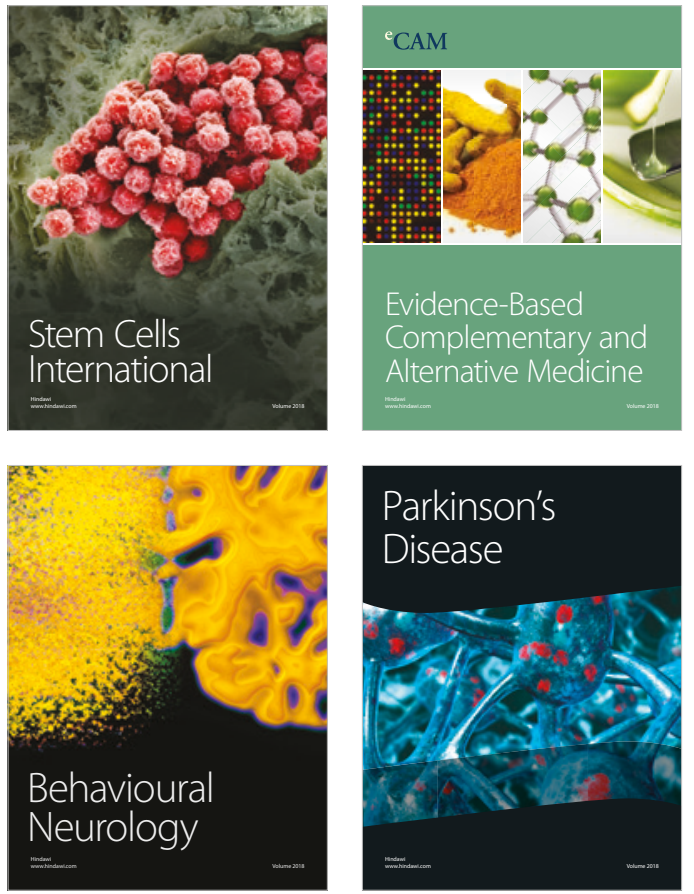

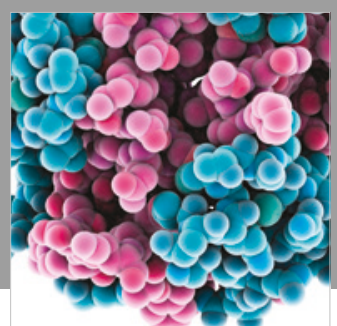

ournal of

Diabetes Research

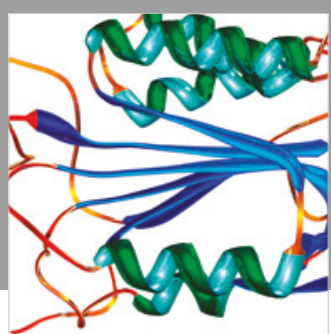

Disease Markers
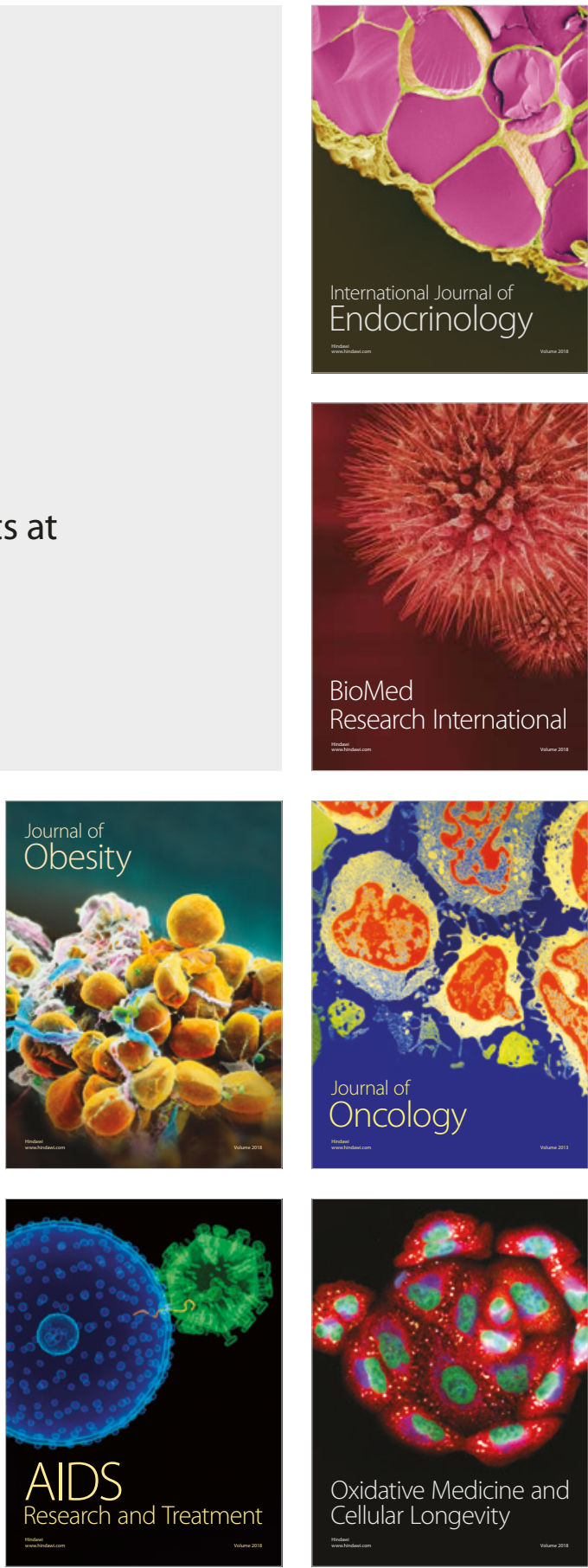